\title{
Higher Habitual Nuts Consumption Is Associated with Better Cognitive Function among Qatari Adults
}

\author{
Hajer Nafea, Omnia Abdelmegid, Sara Qaddourah, Zainab Abdulwahab, Joyce Moawad and Zumin Shi * $\mathbb{D}$ \\ Human Nutrition Department, College of Health Sciences, QU Health, Qatar University, Doha 2713, Qatar; \\ hn1604058@student.qu.edu.qa (H.N.); oa1601767@student.qu.edu.qa (O.A.); sq1703090@student.qu.edu.qa (S.Q.); \\ za1601366@student.qu.edu.qa (Z.A.); jmoawad@qu.edu.qa (J.M.) \\ * Correspondence: zumin@qu.edu.qa; Tel.: +974-4403-6037
}

check for

updates

Citation: Nafea, H.; Abdelmegid, O.; Qaddourah, S.; Abdulwahab, Z.; Moawad, J.; Shi, Z. Higher Habitual Nuts Consumption Is Associated with Better Cognitive Function among Qatari Adults. Nutrients 2021, 13, 3580. https://doi.org/10.3390/ nu13103580

Academic Editor:

Panteleimon Giannakopoulos

Received: 15 September 2021

Accepted: 8 October 2021

Published: 13 October 2021

Publisher's Note: MDPI stays neutral with regard to jurisdictional claims in published maps and institutional affiliations.

Copyright: (C) 2021 by the authors. Licensee MDPI, Basel, Switzerland. This article is an open access article distributed under the terms and conditions of the Creative Commons Attribution (CC BY) license (https:// creativecommons.org/licenses/by/ $4.0 /)$.

\begin{abstract}
The association between nuts intake and cognitive function is inconclusive. We aimed to investigate the association between habitual nuts consumption and cognition among Qatari adults. Data from 1000 participants aged $>20$ years who attended Qatar Biobank (QBB) were used. Nuts consumption was assessed by a food frequency questionnaire (FFQ). Blood samples were measured for magnesium, lipids and glucose. Mean reaction time (MRT) was used as an indicator of cognitive function. Linear regression was used to assess the association. A total of $21.1 \%$ of the participants reported consuming nuts $\geq 4-6$ times/week (high consumption) while $40.2 \%$ reported consuming $\leq 1$ time/month (low consumption). The mean MRT was 715.6 milliseconds (SD 204.1). An inverse association was found between nuts consumption and MRT. Compared to those with a low consumption, high consumption of nuts had a regression coefficient of -36.9 (95\% CI -68.1 to -5.8 ) after adjusting for sociodemographic and lifestyle factors. The inverse association between nuts and MRT was mainly seen among those $>50$ years. There was an interaction between nuts consumption and hypertension. The association between nuts consumption and MRT was not mediated by hypertension, diabetes, or serum magnesium. Habitual higher consumption of nuts is positively associated with cognitive function, especially among old adults.
\end{abstract}

Keywords: nuts consumption; cognition; mean reaction time; adults; Qatar Biobank

\section{Introduction}

Globally, cognitive impairments including Alzheimer's disease and dementia have become a major concern. It has been shown that $42 \%$ of the worldwide population aged $\geq 60$ years were affected by mild cognitive impairment (MCI) [1]. The total number of people with dementia has remarkably increased from 20.2 million in 1990 to 43.8 million in 2016 with women being more affected than men [2]. Dementia was the fifth leading cause of death and accounted for 2.4 million deaths worldwide in 2016 [3]. It has been estimated that a third of dementia cases can be prevented or delayed by interventions to reduce associated risk factors including unhealthy diet, hypertension, diabetes, obesity and depression [4].

The role of diet on the prevention and management of cognitive impairment has been studied in animal studies as well as in human studies [5]. Diet can affect brain function through different mechanisms including the regulation of neurotransmitter pathways, synaptic transmission, membrane fluidity and signal transduction pathways. Many nutrients have been examined for their role in cognitive function (e.g., omega-3 fatty acids, flavonoids, vitamin E) [5]. Nuts are good sources of polyunsaturated fatty acids, phytosterols, polyphenols, and magnesium. Nuts consumption has been shown to be beneficial for the prevention of many chronic diseases including diabetes and hypertension [6]. Since hypertension and diabetes are risk factors for cognitive impairment, it is possible that nuts consumption can improve cognitive function. Few population observational studies have examined the association between nuts consumption and cognitive function. Findings 
from most of these studies suggest a beneficial effect of nuts on cognition [7-10]. For instance, a study conducted on 4822 adults in China found that higher nuts consumption may contribute to a better overall cognition at older ages [9]. On the other hand, few studies showed there is no association between cognitive function and nuts intake [11,12]. For instance, a randomized cross-over trial showed no effect of walnut supplementation on memory, non-verbal reasoning, and mood in young adults [11].

Findings from animal studies suggest a beneficial effect of magnesium on cognitive function [13-15]. In human studies, serum magnesium and magnesium intake have been shown to be positively related to cognitive function [16]. It is unknown whether serum magnesium mediates the association between nuts consumption and cognitive function.

Based on the National Household Income Expenditure Survey 2012-2013 conducted among households in Qatar, on average each Qatari purchased $28 \mathrm{~g}$ of legumes and nuts per day [17]. As nuts consumption is part of the food culture in Qatar, it is feasible to assess the association between nuts consumption and cognitive function.

The aims of the current study were to (1) to assess the association between nuts consumption and cognitive function among the Qatari population; (2) to test whether magnesium, hypertension, and diabetes mediate this association between nut consumption and cognitive function.

\section{Materials and Methods}

\subsection{Study Design and Sample}

Qatar Biobank Study (QBB) is an ongoing cohort study [18]. The baseline of the study started in 2012. By 2018, a total of 15,000 participants were enrolled. QBB gives Qatar University students' project free access to the data of 1000 participants. In the current analysis, 1000 Qatari adults aged 20 years and above were randomly selected by the QBB management team. Using a self-administered questionnaire, socio-demographic information, lifestyle factors, and dietary habits were collected. In addition, medical and family history information were obtained by a nurse interview and a health examination was conducted at Hamad Medical Center, Doha. All protocols of the QBB study were approved by the Hamad Medical Corporation Ethics Committee in 2011 and QBB Institutional Review Board (IRBs) from 2017 onward. The current study was approved under exemption category (Ex-2019-RES-ACC-0163-0086) by the Qatar Biobank.

\subsection{Outcome Variable: Cognitive Function as Indicated by Mean Reaction Time}

Cognitive function was assessed by a computer-based test to measure the mean reaction time (MRT) $[19,20]$. A visual stimulus was used for the evaluation of MRT. In addition to MRT, a paired episodic memory test was conducted. However, the memory test was not used in the current analysis because the variation is very small.

\subsection{Exposure Variable: Nuts Consumption}

A 102 items food frequency questionnaire (FFQ) was used to assess the dietary habits. The FFQ asked participants to report their usual intake of nuts (never or rarely, once a month, 2-3 times per week, once a week, 4-6 times per week, once per day, $\geq 2$ times/day). In the analysis, nuts consumption was recoded into four categories: $\leq 1$ time/month, 1-3 times/month, 1-3 times/week, and $\geq 4-6$ times/week.

\subsection{Covariates}

Age, sex, education, and literacy levels, smoking (non-smokers, ex-smokers, and current smokers), leisure time physical activity level [metabolic equivalent of task (MET), recoded as tertiles], and BMI (overweight is BMI of $25.0-29.9 \mathrm{~kg} / \mathrm{m}^{2}$ and obesity is BMI of $\geq 30 \mathrm{~kg} / \mathrm{m}^{2}$ ) were used as covariates. Medication use for diabetes and hypertension was collected in interviews by nurses and recoded as "yes" or "no". 
Body height and weight were measured and recorded. Diabetes was defined as $\mathrm{HbA} 1 \mathrm{c} \geq 6.5 \%$, random blood glucose $\geq 11.1 \mathrm{mmol} / \mathrm{L}$, fasting blood glucose $\geq 7 \mathrm{mmol} / \mathrm{L}$, or self-reported doctor-diagnosed diabetes [21]. Hypertension was diagnosed as systolic blood pressure $>140 \mathrm{mmHg}$ and/or diastolic blood pressure $>90 \mathrm{mmHg}$ or previous doctor diagnosis. Serum magnesium was measured at Qatar biobank central lab using the automated colorimetric method. The variations coefficients are $0.3-0.8 \%$. Serum magnesium $<0.85 \mathrm{mmol} / \mathrm{L}$ is used to characterize subclinical magnesium deficiency.

\subsection{Statistical Analysis}

A Chi-square test was used to compare the differences between different levels of nuts consumption for categorical variables while ANOVA was used for continuous variables. Three multivariable linear regression models were used to assess the association between nuts intake and MRT. Model 1 was adjusted for gender and age; model 2 was further adjusted for smoking, education, leisure time physical activity levels, and intake of fruit and vegetable; model 3 further adjusted for BMI, hypertension, diabetes, and the use of hypertension and diabetes medications. As serum magnesium was not related to nuts consumption, it was not adjusted in the model. In sensitivity analyses, we adjusted for herbal tea and regular coffee consumption, as they were associated with MRT in our previous study [22]. The multiplicative interaction between nuts consumption and chronic diseases (diabetes and hypertension) in relation to MRT was tested by adding the product term of the two in the linear regression model. In Stata, a command (marginsplot) was used to visualize the interaction. Structure equation model was used to test the direct and indirect effect. As nuts consumption was not associated with blood lipids in this study (data not shown), we did not adjust for blood lipids (i.e., LDL, HDL, and TG) as covariates in the multivariable model. Furthermore, there was no interaction between nuts consumption and blood lipids. All analyzes were carried out using STATA (version 16, Stata Corporation, College Station, TX, USA). We considered $p$ values $<0.05$ (two-tailed) as statistically significant.

\section{Results}

\subsection{Sample Description}

The mean age of the sample was 35.8 (SD 10.3) years (Table 1). In the sample, $21.2 \%$ of the participants consumed nuts $\geq 4-6$ times/week while $40.2 \%$ consumed nuts $\leq 1$ time/month. Nuts consumption was positively associated with age, fruit and vegetable consumption, and dietary supplement use. Across the levels of nuts consumption, there were no differences in smoking, physical activity, BMI, and serum magnesium. The overall levels of leisure time physical activity in this population were low. Half of the study participants were males. The sample mean of the mean reaction times (MRT) was 715.4 milliseconds (204.1 SD). Nuts consumption was positively associated with regular tea, herbal tea, and Arabic coffee consumption.

Age was positively associated but education was inversely associated with MRT (Figure S1). Women had a higher MRT than men.

\subsection{Association between Nuts Consumption with MRT}

Nuts consumption was inversely associated with MRT. After adjusting for age, gender, education, smoking, PA, intake of fruits and vegetables, across nuts consumption of $\leq 1$ time/month, 1-3 times/month, 1-3 times/week, and $\geq 4-6$ times/week, the regression coefficients $(95 \% \mathrm{CI})$ for MRT were 0 (reference), -24.5 ( -56.9 to 7.9$),-24.0$ ( -54.0 to- 5.9 ), and -36.9 ( -68.1 to -5.8 ) (p for trend 0.016) (Table 2). After further adjusting for BMI, hypertension, diabetes, and medication use, the above association became weaker but remained statistically significant. In sensitivity analyses, the association between nuts consumption and MRT was independent of herbal tea or regular coffee consumption. 
Figure 1 showed a significant interaction ( $p=0.024)$ between nuts intake and age in relation to MRT. Among the older age group, those who had nuts consumption $>1$ time/month had a lower MRT than those consumed nuts $\leq 1$ time/month. The beneficial effect of nuts consumption was clearly observed among individuals aged above 50 years old. However, among younger participants, there was no such association.

There was a borderline significant interaction $(p=0.092)$ between nuts consumption and diabetes in relation to MRT (Figure 2). Participants with a low consumption of nuts tended to have a longer MRT. However, no association between nuts and MRT was found among those without diabetes. There was a significant interaction between nuts consumption and hypertension. The beneficial effect of nuts on MRT was only seen among those with hypertension.

Table 1. Baseline sample characteristics by levels of nuts consumption: Qatar Biobank Study ( $\mathrm{n}=1000)$.

\begin{tabular}{|c|c|c|c|c|c|}
\hline Factor & $\begin{array}{c}\leq 1 \text { Time/Month } \\
(\mathrm{n}=402)\end{array}$ & $\begin{array}{c}\text { 1-3 Times/Month } \\
(\mathrm{n}=168)\end{array}$ & $\begin{array}{c}\text { 1-3 Times/Week } \\
(\mathrm{n}=218)\end{array}$ & $\begin{array}{c}\geq 4-6 \text { Times/Week } \\
\quad(n=212)\end{array}$ & $p$-Value ${ }^{1}$ \\
\hline Magnesium (mmol/L) & $0.83(0.06)$ & $0.84(0.06)$ & $0.83(0.06)$ & $0.83(0.06)$ & 0.22 \\
\hline Age & $34.4(9.9)$ & $36.0(10.7)$ & $36.3(9.7)$ & $38.0(10.9)$ & $<0.001$ \\
\hline Gender & & & & & $<0.001$ \\
\hline Male & $189(47.0 \%)$ & $80(47.6 \%)$ & $137(62.8 \%)$ & $94(44.3 \%)$ & \\
\hline Female & $213(53.0 \%)$ & $88(52.4 \%)$ & $81(37.2 \%)$ & $118(55.7 \%)$ & \\
\hline Education & & & & & 0.028 \\
\hline Low & $140(34.9 \%)$ & $64(38.1 \%)$ & $80(36.9 \%)$ & $54(25.5 \%)$ & \\
\hline High & $261(65.1 \%)$ & $104(61.9 \%)$ & $137(63.1 \%)$ & $158(74.5 \%)$ & \\
\hline Smoking & & & & & 0.20 \\
\hline Non & $272(67.7 \%)$ & $123(73.2 \%)$ & $133(61.0 \%)$ & $145(68.4 \%)$ & \\
\hline Smoker & $79(19.7 \%)$ & $27(16.1 \%)$ & $46(21.1 \%)$ & $35(16.5 \%)$ & \\
\hline Ex-smoker & $51(12.7 \%)$ & $18(10.7 \%)$ & $39(17.9 \%)$ & $32(15.1 \%)$ & \\
\hline Leisure time physical activity (MET hours/week) & $4.5(16.2)$ & $7.7(21.2)$ & $6.7(19.1)$ & $7.9(34.1)$ & 0.23 \\
\hline BMI $\left(\mathrm{kg} / \mathrm{m}^{2}\right)$ & $28.2(6.1)$ & $27.9(5.3)$ & $28.8(5.7)$ & $28.0(5.3)$ & 0.40 \\
\hline BMI categories & & & & & 0.53 \\
\hline Normal & $127(31.6 \%)$ & $49(29.2 \%)$ & $55(25.2 \%)$ & $62(29.2 \%)$ & \\
\hline Overweight & $141(35.1 \%)$ & $68(40.5 \%)$ & $86(39.4 \%)$ & $87(41.0 \%)$ & \\
\hline Obese & $134(33.3 \%)$ & $51(30.4 \%)$ & $77(35.3 \%)$ & $63(29.7 \%)$ & \\
\hline Supplement use & $239(59.5 \%)$ & $96(57.1 \%)$ & $129(59.2 \%)$ & $150(70.8 \%)$ & 0.017 \\
\hline Vitamin D and Calcium use & $150(37.3 \%)$ & $60(35.7 \%)$ & $80(36.7 \%)$ & $93(43.9 \%)$ & 0.30 \\
\hline Vegetable intake (times/week) & $14.8(13.0)$ & $16.0(13.3)$ & $17.9(13.0)$ & $22.3(15.7)$ & $<0.001$ \\
\hline Fruit intake (times/week) & $5.6(5.7)$ & $5.4(5.8)$ & $7.2(5.6)$ & $9.8(6.9)$ & $<0.001$ \\
\hline \multicolumn{6}{|l|}{ Tea and coffee drinking (times/week) } \\
\hline Tea & $6.1(7.4)$ & $6.4(7.6)$ & $6.2(7.4)$ & $8.0(8.0)$ & 0.023 \\
\hline Herbal tea & $2.5(4.6)$ & $3.0(4.8)$ & $3.3(5.2)$ & $4.3(6.0)$ & $<0.001$ \\
\hline Karak & $5.8(6.8)$ & $5.2(6.2)$ & $6.1(6.8)$ & $5.0(6.6)$ & 0.26 \\
\hline Arabic coffee & $7.3(7.8)$ & $7.0(7.4)$ & $8.2(7.8)$ & $9.9(8.2)$ & $<0.001$ \\
\hline Instant coffee & $3.1(5.3)$ & $2.8(5.2)$ & $3.1(4.9)$ & $3.2(5.0)$ & 0.84 \\
\hline Regular coffee (e.g., cappuccino) & $2.4(4.9)$ & $1.5(3.7)$ & $2.1(4.2)$ & $2.6(5.1)$ & 0.11 \\
\hline $\mathrm{HbA} 1 \mathrm{C}(\%)$ & $5.5(0.9)$ & $5.5(0.8)$ & $5.6(1.1)$ & $5.6(0.9)$ & 0.69 \\
\hline Hypertension & $37(9.2 \%)$ & $15(8.9 \%)$ & $21(9.6 \%)$ & $23(10.8 \%)$ & 0.91 \\
\hline Diabetes & $44(11.5 \%)$ & $15(9.3 \%)$ & $29(13.7 \%)$ & $28(13.6 \%)$ & 0.52 \\
\hline Insulin use & $6(1.5 \%)$ & $3(1.8 \%)$ & $7(3.2 \%)$ & $3(1.4 \%)$ & 0.45 \\
\hline Diabetes medication other than insulin & $19(4.7 \%)$ & $6(3.6 \%)$ & $17(7.8 \%)$ & $13(6.1 \%)$ & 0.26 \\
\hline Supplement use & $239(59.5 \%)$ & $96(57.1 \%)$ & $129(59.2 \%)$ & $150(70.8 \%)$ & 0.017 \\
\hline Hypertension medication use & $23(5.7 \%)$ & $8(4.8 \%)$ & $9(4.1 \%)$ & $15(7.1 \%)$ & 0.57 \\
\hline Mean reaction time (millisecond) & $721.2(221.9)$ & $711.2(214.9)$ & $703.5(169.7)$ & $719.5(193.2)$ & 0.75 \\
\hline
\end{tabular}

${ }^{1} p$ from ANOVA for continuous measures or chi-square tests for categorical ones.

Table 2. Association ( $\beta$ 95\% CI) between nuts consumption and cognitive function (mean reaction time) among adults attending Qatar Biobank Study $(\mathrm{n}=1000)^{1}$.

\begin{tabular}{|c|c|c|c|c|c|}
\hline & $\leq 1$ Time/Month & 1-3 Times/Month & 1-3 Times/Week & $\geq 4-6$ Times/Week & $p$ for Trend \\
\hline Model $1^{2}$ & 0.00 & $-22.6(-55.4$ to 10.3$)$ & $-18.8(-49.1$ to 11.5$)$ & $-34.2(-64.8$ to -3.7$)$ & 0.030 \\
\hline Model $2^{3}$ & 0.00 & $-24.5(-56.9$ to 7.9$)$ & $-24.0(-54.0$ to 5.9$)$ & $-36.9(-68.1$ to -5.8$)$ & 0.016 \\
\hline Model $3^{4}$ & 0.00 & $-20.4(-53.2$ to 12.5$)$ & $-18.9(-49.3$ to 11.6$)$ & $-31.3(-62.9$ to 0.2$)$ & 0.048 \\
\hline \multicolumn{6}{|l|}{ Sensitivity analyses ${ }^{5}$} \\
\hline Model 2 + herbal tea & 0.00 & $-22.6(-54.8$ to 9.7$)$ & $-22.1(-52.0$ to 7.7$)$ & $-34.2(-65.3$ to -3.2$)$ & 0.026 \\
\hline Model $2+$ regular coffee & 0.00 & $-25.7(-58.0$ to 6.5$)$ & $-24.3(-54.1$ to 5.6$)$ & $-36.3(-67.2$ to -5.3$)$ & 0.017 \\
\hline
\end{tabular}

${ }^{1}$ Values are regression coefficients (95\% CI) from multivariable linear regression. ${ }^{2}$ Model 1 adjusted for age and gender. ${ }^{3}$ Model 2 further adjusted for education, smoking, physical activity, intake of fruit and vegetable. ${ }^{4}$ Model 3 further adjusted for BMI, diabetes, hypertension, and medication for diabetes and hypertension. ${ }^{5}$ In sensitivity analyses, herbal tea or regular coffee consumption was adjusted as continuous variables (times/week). 


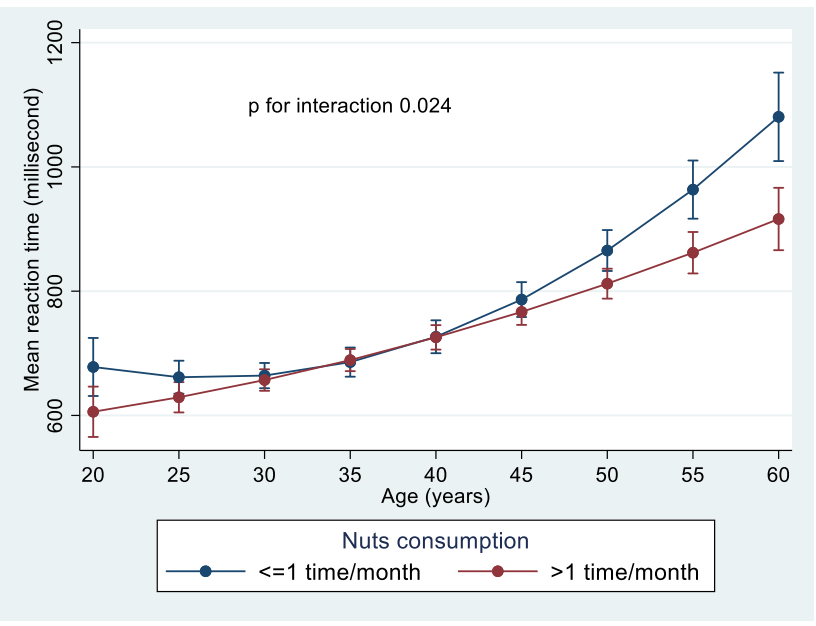

Figure 1. Interaction between nuts intake and age in relation to mean reaction time. Model was adjusted for age, sex, education, and literacy levels, smoking, physical activity level, and BMI.
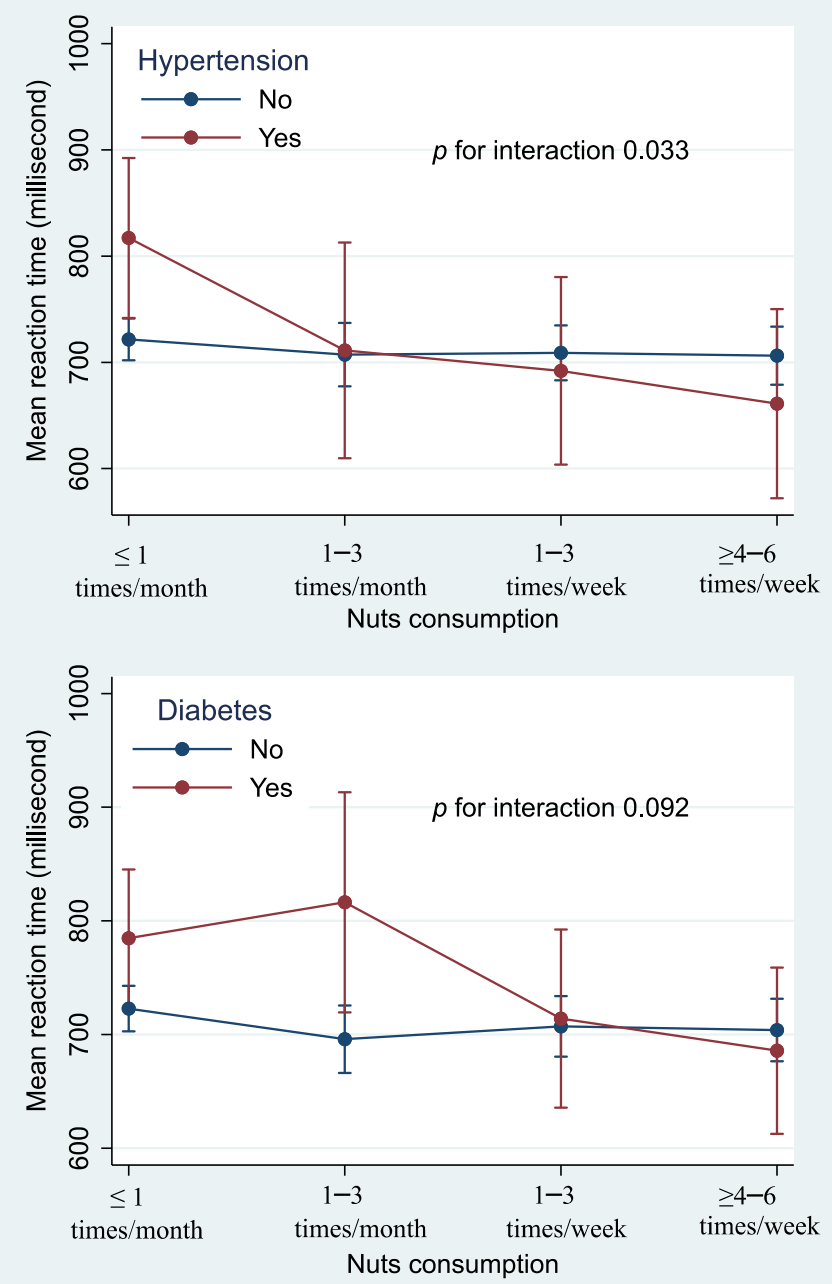

Figure 2. Interaction between nuts consumption and hypertension and diabetes in relation to cognitive function. Models were adjusted for age, sex, education, and literacy levels, smoking, physical activity level, and BMI. 


\section{Discussion}

In this cross-sectional study, nuts consumption was inversely associated with MRT. There was an interaction between nuts consumption and age, hypertension, and diabetes. The inverse association between nuts consumption and MRT was mainly seen among those with an old age, with hypertension, or diabetes. The association between nuts consumption and MRT was not mediated by serum magnesium, hypertension, or diabetes.

The findings of our study were consistent with the results of most of the previous studies in both humans and animals [7-16,23-26]. A cross-sectional study conducted in Spain on 447 participants found that increased intake of Mediterranean-diet components including walnuts is linked to better cognitive function and increased working memory in elderly at high cardiovascular risk [27]. A prospective cohort study of 2613 elderly participants found that high nuts consumption was associated with a better memory, speed, flexibility, and global cognitive score [28]. A prospective cohort study conducted in China ( $\mathrm{n}=4822)$ found that consuming greater than $10 \mathrm{~g} / \mathrm{d}$ of nuts is linked with a higher cognition score and a lower risk of having declined cognitive function [9]. On the other hand, some studies did not find any association between nuts consumption and cognitive function. For example, in a cross-sectional study conducted in Norway, Nurk et al. found that among 2031 males and females aged between 70-74 years there was no significant relationship between nuts consumption and executive function and semantic memory [7]. In the Women's Health Study, among 6174 women aged 75+ years, nuts consumption was not associated with global cognition and verbal memory during a 5-year follow-up [12]. The inconsistent findings may be due to the study design and different levels of nuts consumption as well as the age of participants. In our study, few participants were aged above 65 years.

The interaction between age, hypertension/diabetes, and low nuts intake is intriguing. Hypertension and diabetes are known risk factors for cognitive impairment. If nuts are beneficial for cognitive function, these effects would be more likely to be observed among those who are at risk for cognitive impairment. It may be beneficial to have an adequate intake of nuts especially in older people, and those with hypertension.

\subsection{Clustering of Tea, Coffee and Nuts Consumption}

Nuts consumption is part of the food culture and lifestyle. The types of nuts consumption vary by country. In China, peanuts are the most commonly consumed nuts, followed by chestnut, sunflower seed, pumpkin seed, and walnut [9]. In Arabic countries, hazelnuts, pistachio, and pine tree nuts are commonly consumed. In our study, nuts consumption was positively associated with herbal tea and Arabic coffee consumption. In Qatari culture, it is popular that people eat different types of nuts with Arabic coffee or herbal tea as a snack. Based on our findings, tea and coffee consumption is common among Qatari adults. In a previous study conducted in Qatar, there was a positive association between regular coffee and tea consumption with cognitive function [22]. Furthermore, there was an interaction between tea/coffee consumption patterns and LDL in relation to MRT. A Western coffee consumption pattern was inversely associated with MRT among those with a low LDL. It is possible that the association between nuts consumption and MRT was also partly due to a clustering of eating habits. However, in the current study additional adjustment for tea and coffee consumption did not change the association between nuts consumption and MRT. Unlike the interaction between tea/coffee drinking patterns and LDL, there was no interaction between nuts consumption and lipids in relation to MRT. Thus, the mechanisms linking nuts consumption and MRT may not involve blood lipids.

\subsection{Potential Physiological Mechanisms}

As proposed by previous studies, several mechanisms may explain the association between nuts consumption and cognitive function $[8,10,16]$. First, sufficient nuts consumption is beneficial for the prevention and management of chronic conditions including diabetes and hypertension, which are both considered risk factors of cognitive decline [29,30]. 
Second, nuts contain high levels of antioxidants and can reduce the $A \beta$-induced oxidative stress [31], cell damage, and levels of inflammation [32]. These antioxidants can neutralize the reactive oxygen species (ROS) and decrease the risk of cognition impairment [33]. Moreover, nuts consumption can reduce the risk of cardiometabolic dysfunction and maintain endothelial function [7].

\subsection{Limitations and Strengths}

The study has some limitations. First, MRT is the only indicator used for measuring cognitive function. Other aspects of cognitive functions were not measured. Second, the sample is relatively small and most of the participants were young; therefore, results cannot be extrapolated over the general population. Third, the food frequency questionnaire used included only the frequency of the nuts consumption without specifying the amount or type of the consumed nuts. Thus, we could not estimate the actual amount (grams/day) of nuts intake. In addition, recall bias is considered another limitation in this study. However, this study has several strengths. In the study, a variety of potential confounding factors were measured and adjusted. Chronic conditions were measured including diabetes and hypertension. There is an adequate variation of nuts consumption.

\subsection{Implications of the Study}

This study provides additional information on the association between nuts consumption and cognitive function. Qatar has high rates of chronic non-communicable diseases such as diabetes and hypertension [34], which increase the risk of cognitive impairment [35]. Hypertensive patients with low nuts intake tend to have a poor cognition function in our study. As nuts are an essential part of the Qatari diet [17], promoting nuts consumption in order to prevent chronic disease, including cognitive impairment, is feasible.

\section{Conclusions}

Nuts consumption is beneficial for cognitive function as measured by MRT, especially among those with old age, diabetes, and hypertension. Further prospective studies and randomized clinical trials are needed to assess the amount and type of nuts consumption on cognitive function.

Supplementary Materials: The following are available online at https:/ /www.mdpi.com/article/10 $.3390 /$ nu13103580/s1, Figure S1: Association between sociodemographic and lifestyle factors with cognitive function.

Author Contributions: Conceptualization, Z.S.; methodology, Z.S.; software, Z.S.; validation, Z.S.; formal analysis, H.N., O.A., S.Q., Z.A., J.M. and Z.S.; data curation, Z.S.; writing-original draft preparation, H.N., O.A., S.Q. and Z.A.; writing—review and editing, J.M. and Z.S.; visualization, Z.S.; supervision, Z.S.; project administration, Z.S. All authors have read and agreed to the published version of the manuscript.

Funding: This research received no external funding.

Institutional Review Board Statement: Ethical review and approval were waived for this study, due to the use of secondary de-identified publicly available data.

Informed Consent Statement: Informed consent was obtained from all subjects involved in the study.

Data Availability Statement: The current research uses data from the Qatar Biobank Study. Data described in the manuscript, and code book are available by submitting a request to Qatar Biobank study management team at https:/ / www.qatarbiobank.org.qa/ (accessed on 10 September 2021).

Acknowledgments: We would like to express our special thanks to the Qatar biobank members, staff, and participants for providing us with the appropriate data.

Conflicts of Interest: The authors declare no conflict of interest. 


\section{References}

1. Hu, C.; Yu, D.; Sun, X.; Zhang, M.; Wang, L.; Qin, H. The prevalence and progression of mild cognitive impairment among clinic and community populations: A systematic review and meta-analysis. Int. Psychogeriatr. 2017, 29, 1595-1608. [CrossRef]

2. GBD 2016 Dementia Collaborators. Global, regional, and national burden of Alzheimer's disease and other dementias, 1990-2016: A systematic analysis for the Global Burden of Disease Study 2016. Lancet Neurol. 2019, 18, 88-106. [CrossRef]

3. Prince, M.; Bryce, R.; Albanese, E.; Wimo, A.; Ribeiro, W.; Ferri, C.P. The global prevalence of dementia: A systematic review and metaanalysis. Alzheimers Dement. 2013, 9, 63-75.e62. [CrossRef]

4. Livingston, G.; Sommerlad, A.; Orgeta, V.; Costafreda, S.G.; Huntley, J.; Ames, D.; Ballard, C.; Banerjee, S.; Burns, A.; Cohen-Mansfield, J.; et al. Dementia prevention, intervention, and care. Lancet 2017, 390, 2673-2734. [CrossRef]

5. Gómez-Pinilla, F. Brain foods: The effects of nutrients on brain function. Nat. Rev. Neurosci. 2008, 9, 568-578. [CrossRef]

6. Djoussé, L.; Rudich, T.; Gaziano, J.M. Nut consumption and risk of hypertension in US male physicians. Clin. Nutr. 2009, $28,10-14$. [CrossRef]

7. Barbour, J.A.; Howe, P.R.; Buckley, J.D.; Bryan, J.; Coates, A.M. Nut consumption for vascular health and cognitive function. Nutr. Res. Rev. 2014, 27, 131-158. [CrossRef]

8. Chuang, S.Y.; Lo, Y.L.; Wu, S.Y.; Wang, P.N.; Pan, W.H. Dietary Patterns and Foods Associated With Cognitive Function in Taiwanese Older Adults: The Cross-sectional and Longitudinal Studies. J. Am. Med. Dir. Assoc. 2019, 20, 544-550.e544. [CrossRef] [PubMed]

9. Li, M.; Shi, Z. A Prospective Association of Nut Consumption with Cognitive Function in Chinese Adults Aged 55+ _ China Health and Nutrition Survey. J. Nutr. Health Aging 2018, 23, 211-216. [CrossRef] [PubMed]

10. O'Brien, J.; Okereke, O.; Devore, E.; Rosner, B.; Breteler, M.; Grodstein, F. Long-term intake of nuts in relation to cognitive function in older women. J. Nutr. Health Aging 2014, 18, 496-502. [CrossRef] [PubMed]

11. Pribis, P.; Bailey, R.N.; Russell, A.A.; Kilsby, M.A.; Hernandez, M.; Craig, W.J.; Grajales, T.; Shavlik, D.J.; Sabate, J. Effects of walnut consumption on cognitive performance in young adults. Br. J. Nutr. 2012, 107, 1393-1401. [CrossRef]

12. Samieri, C.; Grodstein, F.; Rosner, B.A.; Kang, J.H.; Cook, N.R.; Manson, J.E.; Buring, J.E.; Willett, W.C.; Okereke, O.I. Mediterranean diet and cognitive function in older age. Epidemiology 2013, 24, 490-499. [CrossRef]

13. Famitafreshi, H.; Karimian, M. Deficit in Memory Is Associated with Paradoxical Regulation of Magnesium and Manganese in Isolated Male Rats. Ann. Neurosci. 2018, 25, 241-246. [CrossRef]

14. Huang, Y.; Huang, X.; Zhang, L.; Han, F.; Pang, K.-L.; Li, X.; Shen, J.-Y. Magnesium boosts the memory restorative effect of environmental enrichment in Alzheimer's disease mice. CNS Neurosci. Ther. 2018, 24, 70-79. [CrossRef]

15. Li, W.; Yu, J.; Liu, Y.; Huang, X.; Abumaria, N.; Zhu, Y.; Huang, X.; Xiong, W.; Ren, C.; Liu, X.G.; et al. Elevation of brain magnesium prevents synaptic loss and reverses cognitive deficits in Alzheimer's disease mouse model. Mol. Brain. $2014,7,65$. [CrossRef]

16. Al-Ghazali, K.; Eltayeb, S.; Musleh, A.; Al-Abdi, T.; Ganji, V.; Shi, Z. Serum Magnesium and Cognitive Function Among Qatari Adults. Front. Aging Neurosci. 2020, 12, 101. [CrossRef]

17. Al-Thani, M.; Al-Thani, A.-A.; Al-Mahdi, N.; Al-Kareem, H.; Barakat, D.; Al-Chetachi, W.; Tawfik, A.; Akram, H. An Overview of Food Patterns and Diet Quality in Qatar: Findings from the National Household Income Expenditure Survey. Cureus 2017, 9, e1249. [CrossRef] [PubMed]

18. Thani, A.A.; Fthenou, E.; Paparrodopoulos, S.; Marri, A.A.; Shi, Z.; Qafoud, F.; Afifi, N. Qatar Biobank Cohort Study: Study Design and First Results. Am. J. Epidemiol. 2019, 188, 1420-1453. [CrossRef]

19. Lyall, D.M.; Cullen, B.; Allerhand, M.; Smith, D.J.; Mackay, D.; Evans, J.; Anderson, J.; Fawns-Ritchie, C.; McIntosh, A.M.; Deary, I.J.; et al. Cognitive Test Scores in UK Biobank: Data Reduction in 480,416 Participants and Longitudinal Stability in 20,346 Participants. PLoS ONE 2016, 11, e0154222. [CrossRef]

20. Al Kuwari, H.; Al Thani, A.; Al Marri, A.; Al Kaabi, A.; Abderrahim, H.; Afifi, N.; Qafoud, F.; Chan, Q.; Tzoulaki, I.; Downey, P.; et al. The Qatar Biobank: Background and methods. BMC Public Health 2015, 15, 1208. [CrossRef] [PubMed]

21. American Diabetes, A. Diagnosis and classification of diabetes mellitus. Diabetes Care 2014, 37 (Suppl. 1), S81-S90. [CrossRef]

22. Heggy, A.; Masoumi, A.; Al-Yafei, M.; Al-Bader, F.; Al-Abdi, T.; Shi, Z. Habitual Tea and Coffee Consumption and Mean Reaction Time Among Qatari Adults. J. Alzheimers Dis. 2021. [CrossRef] [PubMed]

23. Lai, J.S.; Cai, S.; Feng, L.; Shek, L.P.; Yap, F.; Tan, K.H.; Chong, Y.S.; Godfrey, K.M.; Meaney, M.J.; Rifkin-Graboi, A.; et al. Associations of maternal zinc and magnesium with offspring learning abilities and cognitive development at 4 years in GUSTO. Nutr. Neurosci. 2019, 24, 467-476. [CrossRef] [PubMed]

24. Lo, K.; Liu, Q.; Madsen, T.; Rapp, S.; Chen, J.C.; Neuhouser, M.; Shadyab, A.; Pal, L.; Lin, X.; Shumaker, S.; et al. Relations of magnesium intake to cognitive impairment and dementia among participants in the Women's Health Initiative Memory Study: A prospective cohort study. BMJ Open 2019, 9, e030052. [CrossRef] [PubMed]

25. Tu, X.; Qiu, H.; Lin, S.; He, W.; Huang, G.; Zhang, X.; Wu, Y.; He, J. Low levels of serum magnesium are associated with poststroke cognitive impairment in ischemic stroke patients. Neuropsychiatr. Dis. Treat. 2018, 14, 2947-2954. [CrossRef] [PubMed]

26. Parilli-Moser, I.; Domínguez-López, I.; Trius-Soler, M.; Castellví, M.; Bosch, B.; Castro-Barquero, S.; Estruch, R.; Hurtado-Barroso, S.; Lamuela-Raventós, R.M. Consumption of peanut products improves memory and stress response in healthy adults from the ARISTOTLE study: A 6-month randomized controlled trial. Clin. Nutr. 2021. [CrossRef] 
27. Valls-Pedret, C.; Lamuela-Raventós, R.M.; Medina-Remón, A.; Quintana, M.; Corella, D.; Pintó, X.; Martínez-González, M.; Estruch, R.; Ros, E. Polyphenol-rich foods in the Mediterranean diet are associated with better cognitive function in elderly subjects at high cardiovascular risk. J. Alzheimers Dis. 2012, 29, 773-782. [CrossRef]

28. Nooyens, A.C.; Bueno-de-Mesquita, H.B.; van Boxtel, M.P.; van Gelder, B.M.; Verhagen, H.; Verschuren, W.M. Fruit and vegetable intake and cognitive decline in middle-aged men and women: The Doetinchem Cohort Study. Br. J. Nutr. 2011, 106, 752-761. [CrossRef]

29. Biessels, G.J.; Despa, F. Cognitive decline and dementia in diabetes mellitus: Mechanisms and clinical implications. Nat. Rev. Endocrinol. 2018, 14, 591-604. [CrossRef]

30. Tadic, M.; Cuspidi, C.; Hering, D. Hypertension and cognitive dysfunction in elderly: Blood pressure management for this global burden. BMC Cardiovasc. Disord 2016, 16, 208. [CrossRef] [PubMed]

31. Muthaiyah, B.; Essa, M.M.; Chauhan, V.; Chauhan, A. Protective effects of walnut extract against amyloid beta peptide-induced cell death and oxidative stress in PC12 cells. Neurochem. Res. 2011, 36, 2096-2103. [CrossRef] [PubMed]

32. Yu, Z.; Malik, V.S.; Keum, N.; Hu, F.B.; Giovannucci, E.L.; Stampfer, M.J.; Willett, W.C.; Fuchs, C.S.; Bao, Y. Associations between nut consumption and inflammatory biomarkers. Am. J. Clin. Nutr. 2016, 104, 722-728. [CrossRef] [PubMed]

33. Chauhan, A.; Chauhan, V. Beneficial Effects of Walnuts on Cognition and Brain Health. Nutrients 2020, 12, 550. [CrossRef]

34. Ali, F.M.H.; Nikoloski, Z.; Reka, H.; Gjebrea, O.; Mossialos, E. The diabetes-obesity-hypertension nexus in Qatar: Evidence from the World Health Survey. Popul. Health Metr. 2014, 12, 18. [CrossRef] [PubMed]

35. Zilliox, L.A.; Chadrasekaran, K.; Kwan, J.Y.; Russell, J.W. Diabetes and Cognitive Impairment. Current Diabetes Rep. $2016,16,87$. [CrossRef] [PubMed] 